Diabetologia 11, 45-48 (1975)

(C) by Springer-Verlag 1975

\title{
Effect of Ethynodiol Diacetate and Combination - Type Oral Contraceptive Compounds on Carbohydrate Metabolism
}

\section{Six Month Intravenous Glucose Tolerance Study}

\author{
J. A. Goldman \\ Department of Obstetrics-Gynecology, Beilinson Medical Center and Tel-Aviv University Medical School, Israel \\ Received: December 20, 1973, and in revised form: October 22, 1974
}

\begin{abstract}
Summary. In order to evaluate long-term effects of different types of oral contraceptive compounds, blood glucose and plasma insulin levels were measured during an intravenous glucose tolerance test in 2 groups of normal, nondiabetic patients: 36 women using a progesterone-alone oral contraceptive, ethynodiol diacetate, and 36 women using a combinationtype drug, containing norethynodrel and mestranol. Each patient was tested before and after 6 months of treatment. There were no significant differences from pre-treatment glucose and insulin values in the first group of women (on ethynodiol diacetate). In the second group (on norethynodrel and
\end{abstract}

mestranol), there was a significant elevation of mean blood glucose levels at 15,30 and $120 \mathrm{~min}$ of the glucose tolerance test. Nevertheless, a significant elevation of plasma insulin was seen only at $60 \mathrm{~min}$ of the test. Patients participating in this study will continue this treatment, and monitoring of carbohydrate metabolism is contemplated over a period of several years.

Key words: Oral contraceptives, carbohydrate metabolism, glucose tolerance, contraceptive steroids.
Numerous clinical studies have been done on the effects of oral contraceptives on carbohydrate metabolism, following short and long-term use of these drugs. In 1969 Spellacy [1] published an excellent review of carbohydrate metabolism in oral contraceptive users, indicating that further study of the effects in large groups of patients on different parameters of carbohydrate metabolism were necessary in order to elucidate the significance of alterations. In fact, most studies report diabetogenic alterations under the effect of oral contraceptives of the combination-type (estrogen-progesterone).

We have undertaken to follow a group of normal, non-diabetic women attending our family-planning clinic and to evaluate alterations in glucose metabolism, if any, during a longer period, using various types of oral contraceptive steroids.

\section{Material and Methods}

Patients participating in this study were chosen from the family planning clinic of the Beilinson Hospital. Women with a family history of diabetes or history suggestive of prediabetes or latent diabetes were excluded. Also excluded were women who failed to return for all tests and those who had previously been on a steroid preparation or who commenced taking one during the course of the investigation.
Two groups of women, 6 months after delivery participated in this investigation:

\section{Group I}

Thirty-six nonpregnant, parous women were investigated. Their ages ranged from 21 to 35 years, with a mean age of 29 years.

\section{Group II}

Thirty-six nonpregnant, parous women were included in this group. Their ages ranged from 22 to 33 years, with a mean age of 28 years.

Subjects were tested after an overnight fast, and were instructed to take a diet containing a minimum of $300 \mathrm{~g}$ of carbohydrate on each of the 3 preceding days. An intravenous glucose tolerance test (i.v. GTT) was performed as decribed elsewhere [2]. Each patient was given $25 \mathrm{~g}$ of glucose intravenously, and blood samples were obtained before, 15, 30, 60 and $100 \mathrm{~min}$ after completion of the glucose injection. Blood glucose was determined in duplicate by a ferricyanide method adapted to the Technicon AutoAnalyzer [3]. Plasma immunoreactive insulin was determined in duplicate by the method of Hales and Randle [4].

Following the first test, each subject in the first group received one tablet of ethynodiol diacetate ${ }^{1}$ $(0.5 \mathrm{mg})$ daily for 6 months. Each subject in the

1 Ethynodiol diacetate, G.D. Searle \& Co., England. 
second group was instructed to take 21 tablets of Enovid $^{2}$ (a combination-type oral contraceptive, containing norethynodrel $5 \mathrm{mg}$ and mestranol $0.075 \mathrm{mg}$ ) a month for a period of 6 months.

Since each patient was tested before and after taking the contraceptive drug, she served as her own control. The correlated pairs were evaluated statistically by means of Student's $t$ test. A second i. v. GTT was performed on each patient on one of the last days of treatment.

\section{Results}

Mean values for blood glucose and plasma insulin during an intravenous GTT are shown in Tables 1 and 2.

Table 1. Statistical studies (Student's t test) of blood glucose and plasma immunoreactive insulin levels during i.v. GTT in subjects before and after 6 months of oral contraceptive therapy with a progestogen (ethynodiol diacetate, $0.5 \mathrm{mg}$ daily)

$$
(N=36)
$$

a) Blood glucose levels $(\mathrm{mg} / 100 \mathrm{ml})$

\begin{tabular}{lccccc}
\hline & FBS & $15 \mathrm{~min}$ & $30 \mathrm{~min}$ & $60 \mathrm{~min}$ & $120 \mathrm{~min}$ \\
\hline Before & & & & & \\
therapy & & & & & \\
Mean & 79.2 & 201.4 & 171.0 & 93.0 & 80.0 \\
\pm S.D. & 6.4 & 15.9 & 12.6 & 4.9 & 5.3 \\
After & & & & & \\
therapy & & & & & \\
Mean & 80.3 & 201.6 & 170.5 & 92.9 & 80.0 \\
\pm S.D. & 6.0 & 16.0 & 12.9 & 5.0 & 5.8 \\
$t$ & 0.75 & 0.05 & 0.17 & 0.08 & 0.00 \\
$P$ & N.S. & N.S. & N.S. & N.S. & N.S. \\
\hline
\end{tabular}

b) Plasna insulin levels $(\mu \mathrm{U} / \mathrm{ml})$

\begin{tabular}{lrcrcc}
\hline & FPI & $15 \mathrm{~min}$ & $30 \mathrm{~min}$ & $60 \mathrm{~min}$ & $120 \mathrm{~min}$ \\
\hline $\begin{array}{l}\text { Before } \\
\text { therapy }\end{array}$ & & & & & \\
Mean & 18.0 & 75.0 & 36.0 & 20.4 & 19.0 \\
\pm S.D. & 4.5 & 15.8 & 9.0 & 4.7 & 4.5 \\
After & & & & & \\
therapy & & & & & \\
Mean & 17.7 & 75.0 & 35.7 & 20.6 & 19.4 \\
\pm S.D. & 4.5 & 16.1 & 9.4 & 5.0 & 4.5 \\
$\mathrm{t}$ & 0.28 & 0.00 & 0.14 & 0.18 & 0.38 \\
$P$ & N.S.* & N.S. & N.S. & N.S. & N.S. \\
\hline
\end{tabular}

* N.S. = Not significant

\section{Glucose}

The mean values before and after oral contraceptive therapy with ethynodiol diacetate did not differ significantly at any time during the test. The mean

2 Enovid, G. D. Searle \& Co., Chicago, U.S.A. values before and after oral contraceptive therapy with norethynodrel-mestranol did not differ significantly on fasting and after $60 \mathrm{~min}$. However, there was a statistically significant difference at $15 \mathrm{~min}$, $30 \mathrm{~min}$ and at $120 \mathrm{~min}$ (Fig. 1).

Table. 2. Statistical studies (Student's $t$ test) of blood glucose and plasma immunoreactive insulin levels during i.v. GTT in subjects before and after 6 months of oral contraceptive therapy with a combination-type compound (Enovid $\left.{ }^{8}\right)(N=36)$

a) Blood glucose levels $(\mathrm{mg} / 100 \mathrm{ml})$

\begin{tabular}{lcrrcc}
\hline & FBS & $15 \mathrm{~min}$ & $30 \mathrm{~min}$ & $60 \mathrm{~min}$ & $120 \mathrm{~min}$ \\
\hline $\begin{array}{l}\text { Before } \\
\text { therapy }\end{array}$ & & & & & \\
Mean & 82.0 & 190.0 & 172.2 & 90.5 & 76.7 \\
\pm S.D. & 12.2 & 11.9 & 16.6 & 8.6 & 9.7 \\
After & & & & & \\
therapy & & & & & \\
Mean & 86.1 & 215.0 & 187.9 & 91.0 & 83.0 \\
\pm S.D. & 10.3 & 20.7 & 13.7 & 8.7 & 11.2 \\
$\mathrm{t}$ & 1.52 & 6.28 & 4.36 & 0.24 & 2.55 \\
$P$ & N.S. & $\mathrm{S}^{*}$ & $\mathrm{~S}$ & $\mathrm{~N} . \mathrm{S}$. & $\mathrm{S}$ \\
& & $<0.01$ & $<0.01$ & & $<0.05$ \\
\hline
\end{tabular}

* Significant

b) Plasma insulin levels $(\mu \mathrm{U} / \mathrm{ml})$

\begin{tabular}{lccccc}
\hline & FPI & $15 \mathrm{~min}$ & $30 \mathrm{~min}$ & $60 \mathrm{~min}$ & $120 \mathrm{~min}$ \\
\hline $\begin{array}{l}\text { Before } \\
\text { therapy }\end{array}$ & & & & & \\
Mean & 21.0 & 87.6 & 34.0 & 20.0 & 17.0 \\
\pm S.D. & 5.0 & 15.8 & 10.4 & 4.8 & 4.9 \\
$\begin{array}{l}\text { After } \\
\text { therapy }\end{array}$ & & & & & \\
Mean & 22.8 & 86.0 & 34.4 & 23.0 & 18.0 \\
\pm S.D. & 6.9 & 9.8 & 12.6 & 5.1 & 5.2 \\
$\mathbf{t}$ & 1.27 & 0.61 & 0.15 & 2.58 & 0.84 \\
$P$ & N.S. & N.S. & N.S. & S & N.S. \\
& & & & $<0.02$ & \\
\hline
\end{tabular}

\section{Insulin}

The mean values before and after oral contraceptive therapy with ethynodiol diacetate did not differ significantly at any time during the test. The mean value before and after Enovid therapy showed no significant difference during the glucose tolerance test, except at $60 \mathrm{~min}$, when the difference was statistically significant $(P<0.02)$ (Fig. 2).

While many subjects gained some weight early in the course of treatment, no significant changes in weight were registered at the end of the study in either group of women. 


\section{Discussion}

Numerous investigations have established the occurrence of alterations in carbohydrate metabolism after short and long-term use of combination type oral contraceptive drugs $[5,6,7,8]$. In general, they sug-

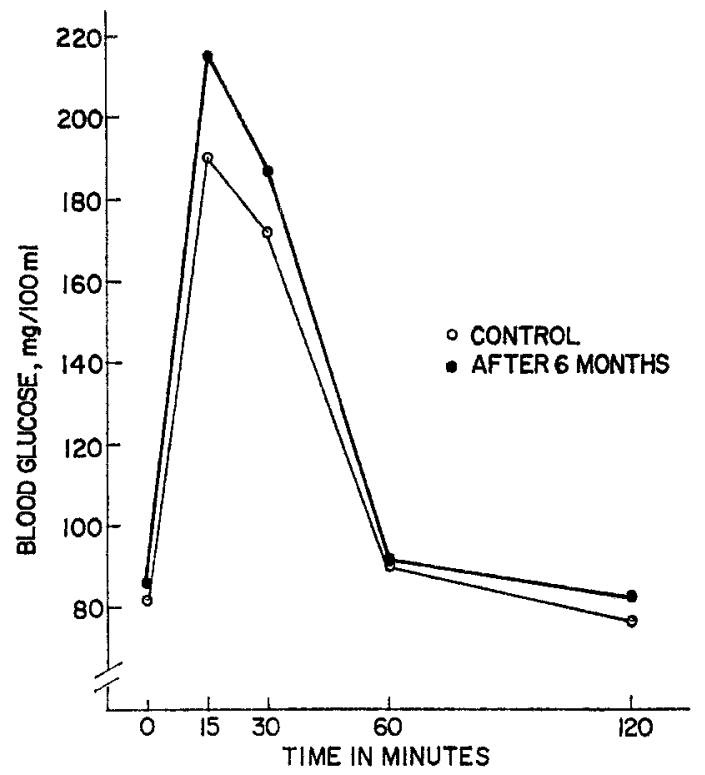

Fig. 1. Mean blood glucose values before and after 6 months of treatment with a combination-type (Enovid) oral contraceptive drug $(\mathrm{N}=36)$

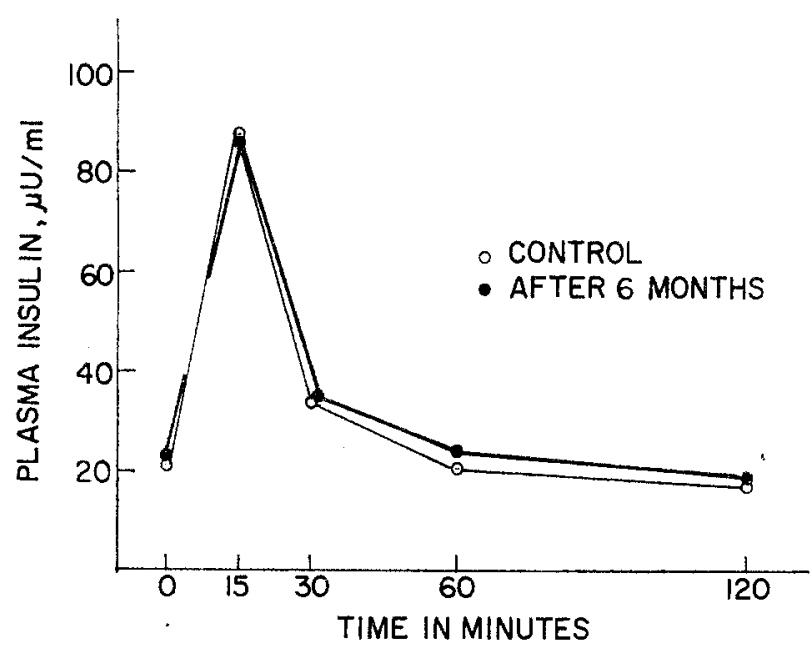

Fig. 2. Mean plasma insulin values before and after 6 months of treatment with a combination-type (Enovid) oral contraceptive drug $(\mathrm{N}=36)$

gest that glucose tolerance is impaired due to the estrogen component of these compounds $[9,10]$. Nevertheless, the role of progesterone in carbohydrate metabolism impairment is controversial; in fact, while most investigators find progesterone to have no effect upon, or even improve glucose metabolism [11, $12,13]$, others have reported a diabetogenic effect of progesterone by means of animal experiments and clinical data $[14,15,16]$. Furthermore, there is no doubt at the present time that contraceptive steroids differ significantly in their effects, according to type of steroid, dosage and duration of therapy, as well as the type of subject.

The present study suggests that oral contraceptive agents containing an estrogen-progesterone combination do possess a diabetogenic effect, while ethynodiol diacetate has no hyperglycemic influence. In fact, no consistent changes were discovered in blood glucose and plasma insulin during an i.v. GTT, when ethynodiol diacetate was used over a period of 6 months.

In order to evaluate long-term effects of the different types of oral contraceptive compounds, we have undertaken to follow-up both our study groups over a period of several years.

Acknowledgements. We are grateful to G. D. Searle \& Co., England, for supplying ethynodiol diacetate. The technical assistance of Mrs. Shoshana Mannheimer, and statistical analysis by Mrs. Zelikson-Singer and Mrs. Rivka Resnik is appreciated.

\section{References}

1. Spellacy, W. N.: A review of carbohydrate metabolism and the oral contraceptives. Amer. J. Obstet. Gynec. 104, $448-469$ (1969)

2. Goldman, J. A., Eckerling, B.: Effect of a progestogen oral contraceptive compound on carbohydrate metabolism. Israel J. med. Sci. 8, 1724-1727 (1972)

3. Hoffman, W. S.: A rapid photoelectric method for determination of glucose in blood and urine. J. biol. Chem. 120, 51 (1937)

4. Hales, C. N., Randle, P. J.: Immunoassay of insulin. Biochem. J. 88, 137 (1963)

5. Goldman, J. A., Eckerling, B., Ovadia, J.: The effect of pseudopregnancy by ovulatory suppressants on the glucose tolerance in women. Fertil. and Steril. 20, 393-399 (1969)

6. Wynn, V., Doar, J. W. H.: Some effects of oral contraceptives on carbohydrate metabolism. Lancet $1966 \mathrm{II}$, $715-723$

7. Yen, S. S. C., Vela, P.: Carbohydrate metabolism and long-term use of oral contraceptives. J. Reprod. Med. 3, 6-18 (1969)

8. Posner, N. A., Silverstone, F. A., Pomerance, W., Baumgold, D.: Oral contraceptives and intravenous glucose tolerance. I. Data noted early in treatment. Obstet. Gynec. 29, 79-86 (1967)

9. Goldman, J. A., Ovadia, J.: The effect of estrogen on intravenous glucose tolerance in women. Amer. J. Obstet. Gynec. 103, 172-178 (1969)

10. Jabor, L. N. A., Tsai, C. C., Vela, P., Yen, S. S. C.: Effect of exogenous estrogen on carbohydrate metabolism in 
post-menopausal women. Amer. J. Obstet. Gynec. 113, 383-388 (1972)

11. Benjamin, F., Casper, D. J.: Alterations in carbohydrate metabolism induced by progesterone in cases of endometrial carcinoma and hyperplasia. Amer. J. Obstet. Gynec. 94, 991-996 (1966)

12. Goldman, J. A., Ovadia, J. L., Eckerling, B.: Effect of progesterone on glucose tolerance in women. Israel J. med. Sci. 4, 878-882 (1968)

13. Beck, P.: Progestin enhancement of the plasma insulin response to glucose in Rhesus monkeys. Diabetes 18, $146-152$ (1969)

14. Schreibman, P. H.: Alteration in carbohydrate and lipid metabolism by a progestin. Diabetes 17, 341 (1968)
15. Haist, R. E.: Factors affecting the islets of Langerhans. Diabetes 2, 295-298 (1953)

16. Ingle, W. J., Beary, D. F., Purmalis, A.: Comparison of effect of progesterone and 11-ketoprogesterone upon glycosuria of partially depancreatized rat. Proc. Soc. exp. Biol. (N.Y.) 82, 416-419 (1953)

Prof. Dr. J. A. Goldman

Dept. of Obstetrics-Gynecology

Beilinson Medical Center and

Tel-Aviv Univ. Medical School

Petach Tikvah

Israel 